Thorax, 1980, 35, 399-400

\title{
Idiopathic pulmonary haemosiderosis treated by plasmapheresis
}

\author{
F POZO-RODRIGUEZ, J M FREIRE-CAMPO, V GUTIERREZ-MILLET, C BARBOSA-AYÚCAR, \\ J DIAZ DE ATAURI, AND P MARTÍN-ESCRIBANO
}

From the Sección de Neumología, Ciudad Sanitaria de la Seguridad Social " $1^{\circ}$ de Octubre", Madrid, Spain

Plasma exchange is a therapeutic technique that may be used to remove pathogenic substances from circulating blood. 1 It has been used in several clinical conditions such as poisoning, thyrotoxicosis, hepatic failure, and specially in immunological diseases. We present a patient with idiopathic haemosiderosis, treated with steroids, immunosuppression, and plasmapheresis.

\section{Case report}

A 52-year-old woman was admitted to our hospital with severe haemoptysis and dyspnoea. She had had repeated haemoptysis starting 18 months before admission and for the last eight months this had cccurred almost daily. Fibreoptic bronchoscopy and a bronchogram had been normal. Several sputa samples were negative for acid-fast bacilli. On admission physical examination showed tachycardia, tachypncea, and normal arterial and central venous pressure. Bilateral diffuse crackles were present. The reart sounds were normal. Chest radiographs showed a moderate alveolar infiltrate at both lung bases. The white cell count was 14000 , haemoglobin $8.8 \mathrm{~g}$, haematocrit $34 \%, \mathrm{MCH} 22 \mathrm{pg}, \mathrm{MCV} 81 \mu \mathrm{m}^{3}$, MCHC $26 \cdot 2 \%$, serum iron $82 \mu \mathrm{g}$, reticulocytes 75000, ESR $65 \mathrm{~mm}$ in one hour, total bilirubin $1.2 \mathrm{mg}$, LDH $581 \mu$, total protein and electrophoresis, vrea and creatinine were normal. ANA, LE cells, rheumatoid factor, Coombs' test and HBsA antigen were negative. There was no proteinuria and the urine sediment was normal. Arterial $\mathrm{PaO}_{2}$ was 55 $\mathrm{mmHg}$ on breathing $35 \%$ oxygen.

Forty-eight hours after admission the patient's condition worsened, dyspnoea and haemoptysis increased, hypoxia was severe and alveolar infiltration kecarre widespread. Treatment with antituberculous drugs, methylprednisone $1 \mathrm{~g}$, and azathioprine $1 \mathrm{CO} \mathrm{mg}$, daily was started. On the sixth hospital day a transbronchial lung biopsy was performed. This showed pulmonary haemorrhage but no infection, vasculitis, necrosis, granulomata, or deposit of immunoglobulins as observed by immunofluorescence. The next day methylprednisolone was reduced to 100

Address for reprint requests: Dr P Martín-Escribano, Sección de Neumología, CSSS “ 1 " de Octubre", Carretera Andalucía Km 5,4, Madrid 26, Spain. mg, and tuberculosis drugs stopped. There was a progressive clinical, radiological, and functional worsening of the patient's condition. On three occasions, the eighth, tenth, and twelfth hospital days, $2000 \mathrm{ml}$ of plasma were changed using manual techniques with disposable plastic equipment and a refrigerated centrifuge PR 6000. The volume of plasma removed was replaced with fresh-frozen plasma. Lung haemorrhage decreased, and dyspnoea, lung infiltrate, and hypoxia improved after the first exchange; all these findings were almost normal after the third exchange (fig). On the fourteenth hospital day $\mathrm{PaO}_{2}$ was 58 $\mathrm{mmHg}$ breathing air and on the nineteenth day chest radiograph showed only a slight interstitial infiltrate at the lung bases. On the thirtieth hospital day a renal biopsy was normal on light and immunofluorescent microscopy. Azathioprine was stopped on the sixtieth hospital day, the patient remaining on $12 \mathrm{mg}$ of methylprednisolone on alternate days. Six months later the patient was asymptomatic with normal ausculation, a normal chest film, and only a slight increase in alveolo-arterial oxygen difference.

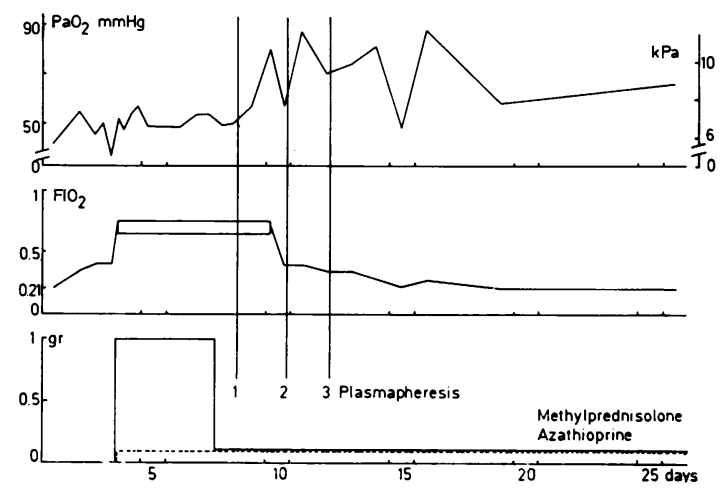

Figure Time course of changes in partial pressure of oxygen in arterial blood $\left(\mathrm{PaO}_{2}\right)$, Fractional concentration of oxygen in inspired air $\left(\mathrm{FIO}_{2}\right)$, and treatment during the 26 hospital days. The three vertical lines represent the days on which the plasma exchange was performed. Between the fourth and the tenth days, oxygen therapy was given with partial mechanical occlusion in the Venturi system of a Ventimask $40 \%$. We consider that the $\mathrm{FIO}_{2}$ in this situation was between 0.65 and 0.75 . Mean barometric pressure in Madrid is $706 \mathrm{mmHg}$. 


\section{Discussion}

Thomas and Irvin ${ }^{2}$ have proposed a classification of diffuse intrapulmonary haemorrhage on the basis of immunopathological features: in idiopathic pulmonary haemosiderosis (IPH), there is no immunoglobulin deposit in lung and kidney, as opposed to Goodpasture's syndrome and immune complex diseases. Therefore the diagnosis of IPH is made by exclusion and it requires lung haemosiderosis without vasculitis, inflammation, necrosis, or granulomata, immunofluorescence absent in lung and kidney, and no clinical or serological criteria of systematic diseases. The aetiology of IPH is unknown. Viral infecticns, exposure to fumes and carbides, cow milk allergy, congenital defects of the alveolar epithelial elastic fibres, vascular disfunction or malformation, basal membrane rupture, ${ }^{3}$ inheritance, ${ }^{4}$ and autoimmune disease have all been suggested in its pathogenesis. Some of these hypotheses justify the use of immunosuppressors as treatment of this condition, ${ }^{5}$ but evaluation of the results is difficult because of the high incidence of spontaneous remissions. Plasmapheresis has been used in several other conditions tut not yet in IPH.

In our case, which fulfils all the diagnostic criteria of IPH, plasmapheresis was followed by clinical, radiological, and functional improvement which had not been previously achieved with methylprednisolonc and azathioprine. The fact that this improvement began immediately after the first exchange and that it was completed after a short time, suggests that it played an important part in the control of the condition in our patient.

In summary we think that, because the high risk? of a fatal outcome from pulmonary haemorrhage in some cases of IPH, rapid control of symptoms is mandatory. The present case showed prompt control with plasmapheresis, supporting the immunopathogenic theory of this rare condition.

\section{References}

1 Pinching AJ. Recent advances in immunologicakr therapy: plasma-exchange and immunosuppres- sion. Br J Anaesth 1979; 51:21-8.

2 Thomas M, Irvin RS. Classification of diffuseo intrapulmonary haemorrhage. Chest 1975; 68: 483-4.

3 González-Crussi F, Hull MI, Grosfeld JL. Idio-⿳亠㐅八 pathic pulmonary haemosiderosis: evidence of capillary basement membrane abnormality. $A m \vec{\bullet}$ Rev Respir Dis 1976; 114:689-98.

4 Thaell JF, Greip PR, Stubbs JE, Siegal CP. Idiopathic pulmonary haemosiderosis. Two cases in a family. Mayo Clin Proc 1978; 53:113-8.

5 Yaeger H, Powell D, Weimberg RM, Bauer H, Ballanti JA, Katz S. Idiopathic pulmonaryō haemosiderosis. Ultrastructural study and re-๊ sponse to azathioprine. Arch Intern Med 1976; 136:1145-9. 